\title{
Tool or Science? The History of Computing at the Norwegian University of Science and Technology
}

\author{
Ola Nordal \\ Department of Computer and Information Science, Norwegian University of Science \\ and Technology (NTNU) N-7941 Trondheim, Norway \\ ola.nordal@hf.ntnu.no
}

\begin{abstract}
One may characterize the history of computing at the Norwegian University of Science and Technology by a tension between the computer as a tool in other disciplines and computer science as discipline in itself. This tension has been latent since the pioneering period of the 1950s until today. This paper shows how this have been expressed in the early attempts to take up computing at the University, and how it gave the Division of Computer Science a fairly rough start when it opened in 1972 .
\end{abstract}

Keywords: Computer history, Computer science, History of computing in academia, Norwegian Institute of Technology (NTH), Trondheim, Norway.

\section{Introduction ${ }^{1}$}

The computer holds several identities - identities that have changed dramatically over a historically very short period. This means that the history of computing is not limited to a study of the technical development of computing machinery, but it also addresses the complex interaction between hardware devices, software devices, the computer as a communication device, and the computer as an information processing device. One of the driving forces in computer history has been the development of computer science in the universities. Despite this, sadly, the history of computing in higher education has received little attention in the historical literature, which is mainly concerned with hardware development or business history. ${ }^{2}$ This omission is

${ }^{1}$ A few words on the background for this paper: In December 2005, the author started organizing a collection of old computers at the Department of Computer and Information Science at NTNU. The goal is to make the collection into a computer museum, and collect historical sources in connection with these machines. The collection is fairly extensive, counting approximately 1000 pieces of hardware, along with a good deal of software and documentation. The most notable objects are two Danish GIER computers (from 1962-1963), two Norwegian NORD-1 computers (from 1969-1970) and one PDP-8 (from 1965). While researching the history of the objects, the work gradually developed into a book project. This article presents some of the themes of this book, which will be due for release some time in 2009. I'm thankful to a number of people for kindly sharing their knowledge on the NTNU Computer history $[21,22,23,24,25,26,27]$.

${ }^{2}$ A notable exception is [11]. In his thesis Campbell examines the rise of electronic computing at the University of Toronto, from the early attempts to obtain a computer in the after war years, to the creation of a Department of Computer Science in 1964. 
especially notable in the few works on European computer history. ${ }^{3}$ In my view, the academic institutions are a good place to study the multiple identities of the computer, and in this article, I will present some aspects of the history of computing at the Norwegian Institute of Technology (NTH) in Trondheim. ${ }^{4}$ The main argument of the article is that the history of computing at NTH is characterized by a tension between the need for the computer as a tool, and the urge to study computing as science.

Computer science had a rather slow start in Trondheim. During the first ten years of the Division of Computer Science that opened in 1972, the teaching load was severe and time for research was limited. Many of the engineering departments at NTH wanted to keep the computer division solely as a service institution in connection with the already existing engineering programs, offering basic programming courses for their students, in the same way as mathematics and other auxiliary subjects. This was due to several reasons. One was that computer science was a relatively new branch of academia, still not regarded as a proper discipline by many. ${ }^{5}$ Another explanation can be sought within the particular history and structure of NTH.

In this article, I will first give a brief overview of the history of NTH to suggest some possible explanations why computing had such a hard time finding its place at the institution. Then I will point to some early attempts to take up computing at NTH, and conclude with an overview of the way the ACM Curriculum' 68 inspired the computer science program in the Division of Computer Science.

\section{The Norwegian Institute of Technology (NTH)}

NTH was established in 1910 as the national institution for educating civil engineers in Norway [13][16][20]. Technological development was seen as the motor that should propel modernization, industrialization and prosperity, and in the Norwegian

\footnotetext{
${ }^{3}$ Another exception is the overview of curricula and research programs at the Nordic universities presented at the previous HiNC conference. See Kurki-Suinio, Reino, Birth of computer science education and research in Finland, Benediktsson, Oddur, Early curricula in computer science at the university of Iceland, and Espelid, Terje O. (et al.), Research and curricula development at Norwegian universities, in [9].

${ }^{4}$ Note on names, abbreviations and institutional development: The Norwegian University of Science and Technology (NTNU) in Trondheim was founded in 1996 as a merger between the Norwegian Institute of Technology (who also used its Norwegian abbreviation NTH in English), the College of Arts and Sciences (AVH), the Museum of Natural History and Archaeology (VM), the Faculty of Medicine, and the Trondheim Conservatory of Music. Since 1968 NTH, AVH and VM had been autonomous parts of a more loosely organized University of Trondheim. The industrial research institute SINTEF (Selskapet for Industriell og Teknisk Forskning, The Institute of Industrial and Technical Research) was founded in 1950, and cooperated closely with NTH. One of the two larger departments in SINTEF were ELAB, the Laboratory for Electrical Research, and RUNIT, the Computer Centre at the University of Trondheim. See [13, 14, 16, 20].

${ }^{5}$ The discipline of computer science emerged in USA during the 1950s and 1960s, and the American Association of Computing Machinerys (ACM) influential curriculum proposal Curriculum '68 propelled the establishment of Computer Science programs in universities all over the world. For an overview on the development of Curriculum '68 and early Computer Science, see [15].
} 
context NTH should be spearheading this development. The structure of NTH reflects the Norwegian industry and political climate in that particular period and defined for a long time which disciplines and departments should be strong and influential. During the period 1905-1920, Norway experienced a great industrial rise, most notably in electrochemical and mining industry. The comparative advantages that Norway had were rich natural resources and cheap electricity from waterfalls and rivers. The modernization of the Norwegian ship industry occurred in this period, and the Norwegian merchant fleet was one of the largest in Europe. The strong departments at NTH were in electrical engineering (mainly focused towards hydropower), chemical engineering, ship and machine construction, and structural engineering.

During the interwar period, Norway and most other European countries went through a series of economical crises, and this halted plans for further development of NTH. This meant that NTH experienced problems due to lack of room and staff, and scarce funding for instrumentation and other necessary investments. They made several attempts and plans for a much-needed expansion of the engineering school, but they could not realize this until after the Second World War.

In the post World War II years, NTH had a slow start due to vacant professorships and an accumulated lack of teaching and laboratory space. During the 1950s and 1960s this gradually changed, and over a period of fifteen years NTH more than quadruplicated its size. Another significant event was the founding of the industry research institute SINTEF in 1950 [14]. SINTEF's main task was to establish a closer connection between NTH and the Norwegian industry. However, it also boosted the expansion and position of NTH, initiated research programs, raised new buildings, and helped with various administrative tasks. Although it was a separate organizational body, the SINTEF activity was always carefully coordinated with the different NTH professors.

\section{The Birth of Computing at NTH/SINTEF}

In the early 1950s, the most "natural" places to take up computing in an institution like NTH would have been either the divisions of mathematics or electrical engineering. However, due to the nature of NTH this proved difficult.

The mathematics department was in the relatively weak Department of General Sciences. The divisions of this department gave auxiliary courses to the engineering students, and, with a notable exception of the division of technical physics, the department did not have its own programs. Research was also limited, except for in the physics division. Werner Romberg, who started out as an associate professor (dosent) in physics in 1950 and was appointed Professor in Applied Mathematics in 1960, made the first attempts to take up digital electronic computing at NTH in the late 1950s. Romberg, being a distinguished mathematician, had previously worked on the differential analyzer at the University of Oslo. He had also been involved in the programming of the first Norwegian computer, NUSSE, which was built in Oslo in 19521954. For some time Romberg was a candidate for the position as director of the 
Norwegian Computing Centre. ${ }^{6}$ He also knew Konrad Zuse and his machines, and he had written vividly about them in the popular science journal Fra fysikkens verden $[18,19]$. Nevertheless, Romberg lacked the political strength and skills needed to realize a pioneering project in Trondheim, and none of his attempts got any support from the founding authorities.

The division of electronics experienced severe problems regaining its strength after the Second World War. The only professor, Ragnar Skancke, had been a part of the national socialistic government during the German occupation, and in 1945 the field was virtually non-existent at NTH. Compared to heavy current technology, electronics had a weak position at the Department of Electrical Engineering until the end of the 1950s. This changed in 1960 when the department finally could move into new and improved buildings. The building plans had been generous, and to exploit the extra space, a SINTEF department for electronic research called ELAB was established [10]. ELAB gave work to many freshly graduated and enthusiastic engineers, and quickly turned out to be one of the most vigorous SINTEF departments.

One of these young engineers was Arne Lyse. After graduating as an engineer in radio technology, he had been working part time and studying computing at the University of Michigan from 1956 to 1959 . He had a fascination for the potential of the capacitor, and even before they established ELAB, he had started a research group in digital technology. This group applied for the funding necessary to develop and build a computer, but failed - partly due to the plans being too ambitious, and that the Norwegian Council for Technical and Scientific research (NTNF) wanted to focus its recourses on the Computer Centre in Oslo [25].

These early attempts show that NTH lacked the right people in the right places, and did not enjoy the necessary support from the Norwegian research councils to take up a pioneering project like for instance the building of NUSSE. Pioneering activity followed another path at NTH. In 1952, NTNF supported Jens Glad Balchen and the Division of Engineering Cybernetics with enough funding to start the development of an analog computer. The first version of the computer DIANA (Differential Analysator) was finished in 1954. However, Balchen was not interested in computer development in itself. He only saw the computer as an important tool that he needed for his discipline. The background for building a computer instead of buying one was that the effort of constructing the machine would give valuable experience to the young engineering cybernetics milieu [17], p. 72. The view of the computer as merely a tool would persist for a long time at NTH.

\section{The Computer Centre at NTH}

In 1962 NTH bought its first digital computer [8]. The choice fell on the Danish GIER, a machine developed and manufactured by Danish Institute of Computer Machinery. To evade formal difficulties with the rigid NTH system and quarrels on who should administrate the machine, they arranged with SINTEF to establish a computer centre as a SINTEF division. Under the leadership of the energetic Norman Sanders,

${ }^{6}$ Letter from Werner Romberg to professor Johan Peter Holtsmark, University of Oslo, dated $31^{\text {st }}$ of December 1950. Private archive Tek. 62: Werner Romberg, NTNU University Library Special Collections, box 1: Correspondence. 
and later Nils Høeg and Karl Georg Schjetne, the Computer Centre at NTH developed into a dynamic service bureau for the Norwegian industry as well as providing computer resources for NTH.

An important aspect in the agreement between NTH and SINTEF was that the computer centre should provide courses for the NTH students. Although this method had been used in many other teaching institutions to handle the lack of academically trained expertise in computing, it was a unique arrangement in the history of NTH. Normally SINTEF research grew out of NTH activity, and it was previously unheard of that the teaching of a discipline solely could be handled by SINTEF. However, this also reflects the view that computing was not regarded as a proper discipline, and thus could be handled by non-academic personnel. During the first years people viewed the courses given more as training in necessary techniques rather than academic subjects.

To some surprise for both the academic staff at NTH and the people working in the computer centre, computing was an immediate hit with the students. Even before any formal course developed, several hundreds of students took voluntarily courses in ALGOL. Over the next decade, several thousand students took courses in programming and other aspects in the use of computers. They introduced approximately one new course each year until 1972 and gradually the courses gained more sophistication and complexity.

The first course in the NTH curriculum that took up digital computing was Rombergs Numerical Methods I and II from 1962-1963. ${ }^{7}$ The courses were compulsory in the first year for students in construction engineering, electrical engineering, and chemistry. They were also elective for students taking a degree in technical physics. Among the topics discussed in Numerical Methods I were linear algebra and programming with "emphasis on methods that could be applied with electronic calculating machines" [2]. In Numerical Methods II, an introduction given to analog and digital computers, as well as elementary programming in ALGOL. However, the focus was on mathematical problems and the introduction to computing was only a limited part of the course.

The first course to focus explicitly on computing was Course no 60: Structure and application of digital computing machines, given by the Computer Centre at NTH in 1963-1964. The course seemed ambitious considering that there were only two lecture hours per week. The topics included history of computing, digital versus analog technology, logic, hardware, software systems on computers, application of computers, autocode, and the more cryptic theme entitled "technology and techniques of the future" [3]. The following year ALGOL was removed from the Numerical Methods II course, and instead a six-week course in ALGOL became compulsory before one could start [4]. Course no 60 had this year changed the name to $A L G O L$, and were compulsory in the third year for chemists, and elective for the other students. Later the subject changed its name to Elementary Programming, taking up other languages as well, but always with an emphasis on ALGOL. Here it should be noted that at $\mathrm{NTH}$, as in most other places, the debate on ALGOL versus FORTRAN as the preferred programming language was fierce and bitter.

\footnotetext{
${ }^{7}$ The course had from 1957 been a part of the auxiliary education in mathematics. Romberg had then given a short introduction to mechanical and electrical computers, without going in detail on how to program or utilize them. Private archive Tek. 62: Werner Romberg, NTNU University Library Special Collections, box 30: Lecture notes.
} 
In the academic year 1970-1971, the computer centre offered a total number of twelve courses [7, p. 16]. These included:

\author{
Programming \\ Computers \\ Intermediate Programming \\ Programming Languages and Compiler Techniques \\ Data Structures \\ Information Systems \\ Project Work \\ SIMULA 67 \\ Computer Systems Simulation \\ FORTRAN \\ COBOL \\ Machine code
}

The first attempt to formalize a curriculum in computing at NTH came in 1969-1970 with a specialization in information processing as one of five combinations leading up to a degree in technical physics. The combination had eighteen courses, of which twelve were courses in mathematics and physics and six were courses given by the computer centre. The Computer Centre developed four new courses especially for this combination [5]. Three associate professors (Terje Noodt, Tore Amble and Kjell Bratbergsengen) were also appointed to help the Computer Centre with the teaching. By this time, elementary programming had become mandatory for all engineering students, but apart from the information processing program there were few possibilities for those wanting to specialize in computing. The list of courses shows that there were some early attempts to take up a more theoretical approach to computing before they could establish a degree in computer science. In fact, at this point, the Computer Centre at NTH taught almost all the basic subjects recommended in the ACM Curriculum' 68.

\title{
5 The Division of Computer Science
}

The discipline of computer science arose in some of the American universities during the late 1950s and early 1960s, often in strong connection with the departments of mathematics or electrical engineering. The key element of computer science was the study of computers "not as a static artifact, but as a system that carried out dynamic processes according to a set of rules" [7, p. 102]. This meant that the focus of computer science was on the study of algorithms, programs, and information, and not the study of computer hardware. Much of this line of thought was put down in the heavily influential curriculum proposal Curriculum ' 68 - a document that it has been said was as important for the development of the computer as the EDVAC report of 1945. In Curriculum'68 a strong emphasis was given to computer organization, system programming, compiler construction, discrete structures, system simulation, and information organization and retrieval [7, p. 106]. During the late 1960s, computer science gradually gained respectability finding a place in most higher education institutions [12, p. 103]. 
At NTH the Division of Computer Science ${ }^{8}$ welcomed its first students in the academic year 1972-1973, and the combination of subjects had a heavy influenced from Curriculum '68.' As Espelid (et al.) points out, this did not fit well into the persisting view on what computing should be at NTH [9, p. 150]. Many had wanted to have computer technology only as a supplementary activity, supporting the already existing curricula in engineering. The reason for this was that many representatives of these communities wanted NTH to focus on the disciplines where the institution already had substantial activity, and not "waste resources" on starting up something completely new. According to this view, the computer department should focus on technical computing, and not on computer science. Nevertheless, it was also clear at the time that there was an emerging need in Norway for engineers holding a full degree in computing, especially since the demand for system developers had increased. In 1969 the socalled Barca-committee estimated that Norway needed another 530 engineers holding a degree in computing each year for the next sixteen years, and the Norwegian universities would not be able to fill this demand if they did not dramatically extend their education in computing [7, p. 12].

The solution at NTH began as a sort of compromise. From 1972 the Division of Computer Science annually admitted approximately twenty students in their third year, giving a specialization in computer systems, technical computing or information systems in the fourth year [7, pp. 26-28]. In addition to this, the division gave elementary programming training to all NTH civil engineering students; approximately $700-800$ students attended each term. Therefore, even though the division only had 40 - 50 full-time computer students and an academic staff of only eight people as late as in 1980, they had to grade more than fifteen hundred examinations annually at the division [1].

One of the reasons for this rather slow start was that the division lacked financial and political support both from the NTH and from NTNF. Most of the funding from the research councils were given to the Computer Centre at NTH. The center had gladly given up its teaching activities, but kept the more profitable research activity. The administrative placement of the Division of Computer Science was another key factor. Before the division was founded, it had been a heated debate on which institutional unit it should be a part of. Suggestions to place it in connection with the existing divisions of mathematics or engineering cybernetics was turned down because both the Computer Centre and NTH feared this would have too much of an impact on the path computing would take at NTH. As a temporary solution, the division was placed at the Department of General Sciences. This secured freedom for the division to develop its own identity. However, it also meant that funding was scarce, since the Department of General Sciences politically and economically was one of the weakest at NTH. A heavy teaching load and almost no time or money for doing research characterized the first years of the Division of Computer Science. The need for a larger academic staff was clearly stated in every annual report from the division throughout

${ }^{8}$ The Norwegian name for the division was Institutt for Databehandling (abbreviated IDB). Sometimes the name is translated into English as the Division of Data Processing.

${ }^{9}$ This does not mean that all computer science influence came from this document. Much inspiration came from cooperating with the other Nordic institutions and especially Börje Langefors and his work on information systems was influential, and already in 1968 the Computing Centre offered a course in information systems [5]. 
the 1970s, but the university granted few new positions [1]. Substantially sized research programs were not granted before the early 1980s. Nevertheless, the field was extremely popular with the students, and the marks required for admission was for many years the highest at NTH. Sometimes this created envy in those departments that still had problems recognizing the need for a full curriculum in computer science at NTH.

From the late 1970s computer science at NTH grew at a steady rate. From 1978 the Division of Computer Science offered a full 41/2-year program, immediately becoming the most popular degree at NTH. During the early 1980s, the financial situation got better and several research programs were initiated. The academic staff also increased dramatically. A closer connection to electronics and communication technology began in 1984 when the Division of Computer Science moved from the Department of General Sciences to a newly formed Department of Electrical Engineering and Computer Techniques. During the 1980s, this department grew to be the largest at NTH.

\section{Concluding Remarks}

It had taken almost twenty years from when they installed the first digital computer at NTH until the Division of Computer Science had reached a substantial size with its own research identity. We can trace much of this back to the division caught between the historically speaking strong engineering divisions at NTH. Moreover, even though the division grew strong and vigorous, the tension between the computer as a tool and the computer as a science has been latent ever since, and we can still see some debates between the computer department and other parts of NTNU.

\section{References}

$\underline{\text { Archives }}$

Private archive Tek. 62: Werner Romberg, NTNU University Library Special Collections

Annual reports, reports etc.

[1] NTH annual reports from the departments and divisions, for the years 1972 to 1980, archive copy at the NTNU Technical Library, in Norwegian

[2] NTH Curriculum 1962-1963, archive copy at the NTNU Technical Library, in Norwegian

[3] NTH Curriculum 1963-1964, archive copy at the NTNU Technical Library, in Norwegian

[4] NTH Curriculum 1964-1965, archive copy at the NTNU Technical Library, in Norwegian

[5] NTH Curriculum 1968-1969, archive copy at the NTNU Technical Library, in Norwegian

[6] NTH Curriculum 1969-1970, archive copy at the NTNU Technical Library, in Norwegian

[7] Virksomhetskomiteen for Regnesenteret ved Norges tekniske høgskole, Utbyggingen av Regnesenteret NTH: Innstilling fra Virksomhetskomiteen for Regnesenteret ved Norges tekniske høgskole. NTH: Trondheim (1970) (The Further Expansion of the Computer Centre at NTH. Report from the Activity Committee for the Computer Centre at the Norwegian Institute of Technology, in Norwegian) (1970) 


\section{$\underline{\text { Literature }}$}

[8] Asphjell, A. (ed.): RUNIT 25 år, 1962-1987. RUNIT, Trondheim) (RUNIT 25 years, 1962-1987)

[9] Bubenko Jr., J., Impagliazzo, J., Sølvberg, A. (eds.): History of Nordic Computing IFIP Wg9.7 First Working Conference on the History of Nordic Computing (HiNC 1), Trondheim, Norway, June 16-18, 2003. Springer, New York (2005)

[10] Børresen, A.K.: Fra tegneøving til regneøving: Om undervisning og forskning innen elektronikk 1945-1970, STS-Rapport 12. Universitetet i Trondheim: Trondheim (1991) (From Drawing Assignments to Calculation Assignments. On Education and Research in Electronics 1945-1970, in Norwegian)

[11] Campbell, S.M.: The Premise of Computer Science: Establishing Modern Computing at the University of Toronto 1945-1965. PhD Thesis, University of Toronto (2006)

[12] Ceruzzi, P.E.: A History of Modern Computing. The MIT Press, Cambridge (2003)

[13] Devik, O.: N.T.H. femti år: Norges tekniske høgskoles virksomhet 1910-1960 (Teknisk Ukeblad: Oslo). (N.T.H. fifty years. Activities of the Norwegian Institute of Technology 1910-1960, in Norwegian) (1960)

[14] Gulowsen, J.: Bro mellom vitenskap og teknologi: SINTEF 1950-2000. Tapir, Trondheim (2000) (Bridge Between Science and Technology: SINTEF 1950-2000, in Norwegian)

[15] Gupta, G.K.: Computer Science Curriculum Developments in the 1960s. IEEE Annals of the History of Computing 29(2), 40-55 (2007)

[16] Hanisch, T.J., Lange, E.: Vitenskap for industrien: NTH - En høyskole i utvikling gjennom 75 år. Universitetsforlaget, Oslo (1985) (Science for the Industry: NTH - a University College in Development Through 75 years, in Norwegian)

[17] Kvaal, S.: Drømmen om det moderne Norge: Automasjon som visjon og virkelighet i etterkrigstiden, STS-Rapport 13. Universitetet i Trondheim, Trondheim (1992) (The Dream of the Modern Norway. Automation as Vision and Reality in the Post War Years, in Norwegian)

[18] Romberg, W.: Om utviklingen av relé- og elektroniske regnemaskiner. Fra fysikkens verden 11(2), 84-98 (1949); (On the Development of Relay and Electronic Calculating Machines, in From the World of Physics, in Norwegian)

[19] Romberg, W.: Zuses relé-regnemaskin. Fra fysikkens verden 11(3), 179-185 (1949); (The Relay Calculating Machines of Zuse, in From the World of Physics, in Norwegian)

[20] Wittje, R.: The foundation of N.T.H. in 1910 in International Context in Sørensen, Henrik Kragh and Reinhard Siegmund-Schultze. Perspectives on Scandinavian Science in the Early Twentieth Century, Novus forlag, Oslo, pp. 111-132 (2006)

Interviews (by the author)

[21] Jens Glad Balchen (26.04.2006)

[22] Kolbein Bell (11.07.2006)

[23] Kjell Bratbergsengen (29.06.2006) (17.08.2006)

[24] Aasmund Gjeitnes (31.08.2006)

[25] Johannes Moe (27.06.2006)

[26] Karl Georg Schjetne (10.02.2006)

[27] Arne Sølvberg (18.08.2006) 